\title{
Spatial distribution and hotspots of mammals in Canada
}

41 Department of Biology, McGill University, 1205 Ave Dr Penfield, Montréal, Québec, Canada, H3A 1B1

2 Department of Biology, Université de Sherbrooke, 2500 boul. de l’Université, Sherbrooke, Québec, Canada, J1K 2R1

9 Key words: Endangered species; Conservation; Species richness; Protected areas;

10 Range-edge populations; Species distributions

11

12 Correspondent: Anna L. Hargreaves - anna.hargreaves@mcgill.ca

13

14 Acknowledgements: Funds for this work were provided by NSERC (Discovery grant to

$15 \mathrm{ALH}$ ) and the E. Gordon Edward fund in support of undergraduate research in biology at

16 McGill University. We thank Pascale Caissy for her help with QGIS. 


\section{Abstract}

18 High-latitude countries often contain the polar range edge of species that are common

19 farther south. The more peripherally a species occurs in a country, the smaller its national

20 range will be and the more its national range will consist of range-edge populations,

21 which are often predicted to be relatively small, isolated, and unproductive. Together, this

22 may focus national conservation efforts toward peripheral species whose global

23 conservation value is controversial. However, if range-edge taxa occur where overall

24 diversity is also high, there would be fewer trade-offs in protecting them. Using 153 of

25 the 158 terrestrial mammal species in Canada, we tested how species' distributions relate

26 to their national conservation status and total mammal richness. Half of 'Canadian'

27 mammals had $<20 \%$ of their global range in Canada. Range area in Canada was strongly

28 associated with national threat status; mammals considered 'at-risk' in Canada had 42\%

29 smaller Canadian ranges than mammals considered secure. However, after accounting for

30 range area, being more peripheral (smaller proportion of global range in Canada) did not

31 increase the likelihood that a taxon was considered at-risk. We overlaid the 153 maps to

32 calculate mammal diversity across Canada, divided into 100x100 km grid cells. We

33 found that hotspots of at-risk mammals (cells with $>4$ at-risk taxa) and hotspots of range-

34 edge mammals (cells with $>12$ taxa with $\leq 20 \%$ of their range in Canada) were about

35 twice as species rich as non-hotspot cells, containing up to $44 \%$ of Canadian mammal

36 diversity per grid-cell. Our results suggest that protecting areas with the most at-risk or

37 range-edge mammals would simultaneously protect habitat for many species currently

38 deemed secure. 


\section{Introduction}

40 Large polar countries often contain the high-latitude range edge of many species that are

41 more widely distributed beyond their borders (Cheffings et al. 2005; Gibson et al. 2009;

42 Rassi et al. 2010; ArtDatabanken 2015). For a given species, the more peripherally it

43 occurs in a country, the smaller its national range area will be. Thus range-edge taxa that

44 occupy small areas in a country are more likely to be deemed nationally at-risk (Lesica \&

45 Allendorf 1995), especially if range-edge populations themselves are smaller, more

46 isolated, or less productive than more central populations (Brown et al. 1996; Sagarin \&

47 Gaines 2002; Yakimowski \& Eckert 2007; although this pattern is far from universal;

48 Samis \& Eckert 2009; Pironon et al. 2017; Hargreaves \& Eckert 2019). Conservation in

49 large polar countries may therefore be focused toward range-edge species even for taxa

50 that are globally secure (Hunter \& Hutchinson 1994).

52 The value and practicality of conserving range-edge populations are contentious.

53 Ethically, some argue that countries have the greatest obligations to taxa with the largest

54 percentage of their range in their borders, and that taxa are not truly at-risk if they are

55 globally secure (Hunter \& Hutchinson 1994). Practically, edge populations may be

56 difficult to conserve if they are inherently unstable due to small numbers, low genetic

57 diversity, or poor habitat (Hunter \& Hutchinson 1994; although again these patterns do

58 not hold for many taxa; Eckert et al. 2008). On the other hand, range-edge populations

59 can be important for diversification if they occupy unique habitats (Van Rossum et al.

60 2003; Mimura \& Aitken 2010), and natural range expansion following gradual local

61 adaptation (Hargreaves \& Eckert 2019). Polar edge populations are also geographically 
62 poised to initiate range shifts in response to climate warming (Gibson et al. 2009). The

63 geographic 'head start' edge populations offer is especially important when species'

64 dispersal ability is low compared to the rate of climate change, as is the case for many

65 terrestrial mammals (Thomas et al. 2004; Schloss et al. 2012).

67 Evaluating the relative conservation merits of range-edge taxa would be less important if

68 protecting edge populations involved few conservation trade-offs. One important

69 conservation strategy is establishing protected areas (Myers et al. 2000; Le Saout et al.

70 2013). Protected areas will be most effective if multiple levels of biodiversity co-occur

71 (Prendergast et al. 1993; Myers et al. 2000; Ricketts et al. 2005), e.g. if at-risk or range-

72 edge species occur in areas with high species richness. Previous studies have not found

73 significant co-occurrence of rare or threatened taxa and overall species richness, either at

74 a global scale for vertebrates (Orme et al. 2005; Ceballos \& Ehrlich 2006; Jenkins et al.

75 2013), or within the UK for invertebrates, plants and birds (Prendergast et al. 1993).

76 However, co-occurrence may be more likely in large high-latitude countries if range-edge

77 taxa are often considered nationally at-risk, since edge taxa and biodiversity will be

78 concentrated toward the equatorward border of such countries (Buckley et al. 2010).

80 We explore the co-occurrence of at-risk and range-edge taxa with overall richness using

81 terrestrial mammals in the world's second largest country: Canada. Canadian mammals

82 provide an excellent case study as distribution maps and national threat ranks are

83 available for each taxon (usually species but sometimes subspecies or populations), and

84 Canada's conservation assessment body-the Committee on the Status of Wildlife in 
85 Canada (COSEWIC)-uses IUCN criteria that emphasize local abundance and range area.

86 Protection of edge populations in Canada is also of global conservation significance, as

87 Canada contains the highest latitude refuges for species in the Americas. Many species

88 designated 'at-risk' in Canada are range-edge populations of species largely distributed

89 outside Canada (Gibson et al. 2009; Klemet-N'Guessan et al. 2019), but previous

90 estimates have not compared at-risk to secure taxa or quantified range areas in Canada. It

91 is therefore unclear whether so many at-risk taxa are peripheral simply because most taxa

92 in Canada are peripheral, because edge populations have smaller range areas in Canada,

93 or because edge populations are inherently more at risk.

95 Using IUCN range maps available for 153 of the 158 extant mammal species that occur

96 in Canada, and categorizing each taxon as nationally at-risk or secure based on its

97 COSEWIC status, we asked two questions. Question 1) How do range area in Canada and

98 the proportion of a taxon's global range in Canada (lower means more peripheral) relate

99 to national conservation status? We predicted that: a) at-risk taxa will have smaller

100 Canadian ranges given the link between range area and population size (Lawton 1993)

101 and importance of both for conservation; b) at-risk taxa will have smaller percentages of

102 their range in Canada given previous findings that many at-risk taxa are edge populations

103 (Gibson et al. 2009; Klemet-N'Guessan et al. 2019); and c) that smaller range

104 percentages would increase the probability that a taxon is at risk even after controlling for

105 range area, if edge populations routinely suffer from factors that would increase their

106 conservation risk (Coristine \& Kerr 2011). We then divided Canada into 100x100 km

107 grid-cells and asked Question 2) Do cells with the high richness of at-risk species or 
108 range-edge species (hotspots) occur in regions of high overall mammal richness? If

109 range-edge populations are over-represented among at-risk species, as predicted in

110 Question 1, and since edge populations and species richness should both cluster toward

111 Canada's low-latitude border, we predict that at-risk and range-edge hotspots will have

112 higher total mammal richness than non-hotspot cells.

\section{Methods}

115 We recorded the Canadian conservation status for each mammal taxon from COSEWIC 116 assessments; we used COSEWIC's recommendation rather than official status under the

117 Species at Risk Act (SARA) as COSEWIC addresses only conservation risk whereas

118 SARA also considers the economic impact of a given listing. Taxa per threat category: 10

119 Special concern, 5 Threatened, 7 Endangered, 8 assessed as Not at Risk. The remaining

120123 mammal taxa had not been assessed. As COSEWIC assesses species in order of

121 perceived risk, we assume that those that have not been assessed in the 41 years of

122 COSEWIC assessments are relatively secure. Given the low sample sizes within at-risk

123 categories, we binned taxa as either 'at-risk' (Special Concern, Threatened, or

124 Endangered) or 'secure' (assessed as Not at Risk or not assessed).

126 We obtained distribution maps in the form of spatial polygons from the International

127 Union for Conservation of Nature (IUCN 2018). We first selected the 158 terrestrial

128 mammal species whose distribution polygon overlapped a polygon map of Canada

129 (Natural Earth 2018). IUCN maps are by species, but COSEWIC sometimes assesses

130 subspecies or populations. We retained subspecies and populations if the distribution map 
131 provided in their COSEWIC assessment was similar to their IUCN distribution polygon

132 (2 subspecies and 1 population), but discarded 5 at-risk taxa whose IUCN polygons did

133 not match the geographic scale of their COSEWIC assessments. This yielded 153 taxa:

134150 species, 2 subspecies, and 1 population (153 unique species in total; Fig. 1). Each

135 map was cropped to land only by overlapping it with a world boundary map (Natural

136 Earth 2018) using the "sf" package ( version 0.7-3, Pebesma 2018) in the statistical

137 platform R (version 3.5.1, R Core Team 2018). As we were interested in range area,

138 polygons were projected into Albers equal area projection (Gibson et al. 2009).

140 Q1) How do range area in Canada and range percentage in Canada relate to national

141 conservation status?

142 We determined each taxon's range area and range percentage in Canada using the "sf"

143 package. We determined range area in Canada $\left(\mathrm{km}^{2}\right)$ by overlapping each species' map

144 with a boundary map of Canada (Natural Earth 2018), then measuring the area of the

145 overlap. Canadian range area varied from $2 \mathrm{~km}^{2}$ (Lontra canadensis) to $>9$ million $\mathrm{km}^{2}$

146 (Nycticeius humeralis), with mean $=1678850 \mathrm{~km}^{2}$ and median $=460130 \mathrm{~km}^{2}$. Due to

147 the large spread of range areas, we ln-transformed Canadian range area for analyses (see

148 below). We quantified each taxon's global range area by measuring the area of overlap

149 between its range map and a global land map. Global range area varied from $2075 \mathrm{~km}^{2}$

150 (Marmota vancouverensis) to $>22$ million $\mathrm{km}^{2}$ (Puma concolor), with mean $=4449710$

$151 \mathrm{~km}^{2}$ and median $=3263110 \mathrm{~km}^{2}$. We calculated the percentage of each taxon's global

152 range that occurs in Canada (i.e. the inverse of peripherality in Canada) as Canadian 
153 range area/Global range area $\times 100$; this varied from $<0.001 \%$ (Nycticeius humeralis) to

154 100\% (Dicrostonyx nunatakensis \& Marmota vancouverensis).

156 We tested the relationships between range area in Canada, range percentage in Canada,

157 and conservation status in Canada using three models. We tested whether range area

158 (ln(range area), gaussian response; model $a$ ) or percentage (proportion response; model $b$ )

159 in Canada differed between taxa deemed at-risk or secure (conservation status = binomial

160 predictor), using generalized linear models (GLMs) with a gaussian and binomial error

161 structure, respectively ( $g l m$ command, base R; $\ln ($ range area) or percentage

162 conservation status). Next, using a binomial GLM we tested whether the probability of a

163 taxa being at-risk (conservation status = binomial response) varied with range percentage

164 in Canada (proportion predictor) even after accounting for range size (continuous

165 predictor; model $c)$ : conservation status $\sim \ln ($ range area $)+$ range percentage (Venables $\&$

166 Ripley 2002). We assessed the significance of predictors using likelihood ratio Chisquare

167 tests (Anova type=III command, car package).

169 Q2) Do hotspots of at-risk or range-edge taxa coincide with high overall diversity?

170 To quantify the spatial distribution of mammal diversity, we overlaid a grid of $100 \times 100$

$171 \mathrm{~km}$ cells on the Canadian equal area map. This produced a map of Canada divided into

1721285 cells (not all equal in area as the Canadian border bisected some cells; Supporting

173 Information). We overlaid the range map polygons of all terrestrial mammals on the grid

174 map, then counted the total mammal species, at-risk species, and range-edge species in

175 each cell. We defined 'range-edge species' as taxa with $\leq 20 \%$ of their global range in 
176 Canada (as per Klemet-N'Guessan et al. 2019); using a threshold of $10 \%$ reduced the

177 number of range-edge taxa from 76 to 53 but did not alter conclusions to Questions 1 and

1782 (Supporting Information). Following Prendergast et al. (1993) and Reid (1998), we

179 identified cells with the highest richness ('hotspots') of at-risk and of range-edge taxa up

180 to a maximum of 5\% of the total grid cells. We use 'hotspot' sensu Prendergast et al.

181 (1993) to refer to areas with high biodiversity, rather than sensu Myers (1988) as areas of

182 high diversity and high extrinsic threat. This yielded 47 hotspot cells for at-risk taxa (5 to

1836 at-risk taxa/cell; $3.6 \%$ of total grid cells; Fig. 2 a), and 47 hotspot cells for range-edge

184 taxa (17 to 29 range-edge taxa/cell; Fig. 2b). Cells containing 4 at-risk or 16 range-edge

185 taxa were not counted as the number of hotspot cells would have exceeded $5 \%$ of total

186 cells. This method of identifying cells of high richness creates richness indices that are

187 reasonably independent of total species richness (Reid 1998).

189 Whereas regression models assume data points are independent, we detected significant

190 spatial autocorrelation; i.e. hotspot cells for at-risk taxa occurred closer to each other than

191 expected by chance (Moran’s $I \pm \mathrm{SD}=0.0628 \pm 0.00137, P<0.001$ ), as did range-edge

192 hotspots (Moran's $I \pm \mathrm{SD}=0.116 \pm 0.00137, P<0.001$ ). We accounted for this spatial

193 autocorrelation by incorporating the spatial configuration of data via a fixed effect

194 covariate $(s)$, using the Spatial Eigenvector Mapping method (Griffith \& Peres-Neto

195 2006; Dormann et al. 2007; Thayn \& Simanis 2013). We selected the neighborhood size

196 of the spatial configuration covariate using the value that maximized model fit based on

197 its Akaike Information Criterion (AIC) value (Supporting Information, Augustin et al. 
198 1996; Dormann et al. 2007). Including $s$ as a fixed effect corrected the autocorrelation in

199 residuals and improved model fit (Supporting Information).

201 We tested whether total mammal richness was higher in at-risk hotspots than other cells

202 using a GLM with binomial error structure. Each cell contributed one data point. The

203 cells' at-risk hotspot status (at-risk hotspot or not) was a binomial response, and total

204 mammal richness and the spatial covariate $s$ were fixed effects (at-risk hotspot $\sim$ total

205 richness $+s$ ). Significance of predictors was determined using likelihood ratio Chisquare

206 tests as for Question 1. This approach is consistent with previous studies comparing at-

207 risk vs. total richness (Prendergast et al. 1993; Orme et al. 2005; Ceballos \& Ehrlich

208 2006), but we recognize two complicating issues: first, that the response and predictors

209 are not fully independent as an increase in at-risk richness automatically increases total

210 richness; second that smaller cells (bisected by the Canadian border) may contain fewer

211 species due to sampling error. We ran two alternate GLMs to test whether our results

212 were sensitive to either issue, one with richness of secure mammals as the predictor (at-

213 risk hotspot $\sim$ secure mammal richness $+s$; Supporting Information), and one including

214 cell area as a fixed effect (Supporting Information). Both models reached the same

215 conclusions as our original model, so we present analyses using total richness and not

216 including cell size to facilitate comparison with previous studies.

218 Similarly, we tested whether total mammal richness was higher in hotspots of range-edge

219 taxa richness than other cells (range-edge hotspot $\sim$ total richness $+s$ ). Results using 
220 richness of secure mammals instead of total richness were again similar (Supporting

221 Information).

222

223 Results

224 In Canada, mammal richness is highest toward the south and along the western mountains

225 (Fig. 1a, Fig 2. grey scale maps), although this pattern was not apparent for the 22 taxa

226 deemed at-risk (Fig. 1b). Half (50\%) of all 'Canadian' mammals had less than 20\% of

227 their global range in Canada.

228

229 Q1) How do range area in Canada and range percentage in Canada relate to national

230 conservation status?

231 Range area in Canada differed significantly between nationally at-risk and nationally

232 secure mammals, but peripherality did not (Fig. 1). As predicted, mammals at-risk of

233 extinction in Canada had smaller Canadian ranges than mammals considered secure

234 (model a: $X_{\mathrm{df}=1}^{2}=6.28, P=0.012$; Fig. 1c). Contrary to our predictions, at-risk mammals

235 did not have smaller fractions of their global ranges in Canada (model b: $X_{\mathrm{df}=1}^{2}=0.39, P$

$236=0.53$; Fig. 1d). Probability of being at-risk in Canada increased as Canadian range area

237 decreased (area: $X_{\mathrm{df}=1}^{2}=4.54, P=0.033$ ), but was not affected by range percentage in

238 Canada after controlling for range area (percentage: $X_{\mathrm{df}=1}^{2}=0.06, P=0.85$, model c).

240 Q2) Do hotspots of at-risk or range-edge taxa coincide with high overall diversity?

241 Of the $1285100 \times 100 \mathrm{~km}$ grid cells in Canada, cells with the highest richness of at-risk

242 and range-edge mammals ('hotspots') coincided with areas of high total richness (Fig. 2). 
243 Hotspots of at-risk mammals had significantly higher total mammal richness than other

244 cells $\left(X_{\mathrm{df}=1}^{2}=140.3, P<0.0001\right.$; Fig. 2 c). At-risk hotspot cells each contained 37 to 67

245 mammal species (24-44\% of Canada's mammal richness; Fig. 2c), and together were

246 home to $80 \%$ of the 153 Canadian mammals in our data. Similarly, hotspots of range-

247 edge species, i.e. species only present in Canada in $\leq 20 \%$ of their range, also had

248 significantly higher mammal richness than other cells $\left(X_{\mathrm{df}=1}^{2}=266.8, P<0.0001\right.$; Fig.

$2492 \mathrm{~d})$. Range-edge hotspot cells each contained 41 to 67 mammal species $(27-44 \%$ of

250 Canada's mammal richness), and together were home to $81 \%$ of the 153 Canadian

251 mammals in our data. The two types of hotspot partially coincided with each other:

252 almost a third of at-risk hotspot cells were also range-edge hotspots and vice versa (15 of

25379 hotspot cells overlapped; Fig. 2).

\section{Discussion}

256 Our quantitative analyses of how mammals are spatially distributed in Canada revealed

257 three main findings. First, our results confirmed earlier qualitative assessments

258 (Yakimowski \& Eckert 2007; Gibson et al. 2009) that Canada is a land of edge

259 populations; half the mammals that live in Canada only do so at the northernmost $20 \%$ or

260 less of their global range. Second, by quantifying range area we showed that species with

261 smaller Canadian ranges are more likely to be nationally at-risk (Fig. 1a), but that species

262 with smaller fractions of their range in Canada were not (Fig. 1d and model c). Thus we

263 found no evidence that range-edge populations are inherently more vulnerable due to

264 their demography (e.g. putatively small or isolated populations) or coincidence with areas

265 of high human population density. Third, we found significant spatial overlap between 
266 high mammal diversity and hotspots of both at-risk mammals and range-edge mammals

267 (Fig. 2). This result is particularly exciting, as it suggests that protecting habitat for at-

268 risk mammals could have significant co-benefits to mammals considered secure, and that

269 protecting range-edge populations need not involve a trade-off with protecting Canada's

270 overall mammal diversity.

272 Our finding of high spatial overlap between total mammal richness and at-risk mammal

273 richness (Fig. 2c) contrasts results from other areas and taxa. Globally, hotspots of at-risk

274 mammals do not strongly overlap areas of high total mammal richness (Ceballos \&

275 Ehrlich 2006), nor do hotspots of at-risk birds strongly overlap with hotspots of total bird

276 richness (Orme et al. 2005). Diversity is driven largely by energy availability and

277 biogeographic history (Gaston 2000), whereas threats to wildlife are driven by human

278 impacts (Schipper et al. 2008; Szabo et al. 2012). Poor global congruence between at-risk

279 and total diversity suggests these drivers have different global distributions (Orme et al.

280 2005). In Canada however, mammal richness concentrates in the south and west (Fig. 1),

281 as does the intensity of human land conversion (Kerr \& Cihlar 2004; Kerr \& Deguise

282 2004). To the extent that diversity and human impacts co-occur in other high-latitude

283 countries, high overlap between at-risk and total diversity may be more common at

284 regional than global scales.

286 Of course, habitat protection generally happens on a much smaller scale than our

$287100 \times 100 \mathrm{~km}$ grid cells, and species rarely occupy all land area within their occurrence

288 polygon at fine scales. Protecting habitat within a hotspot may not capture all the species 
289 whose ranges overlap with the larger grid cell. Nevertheless, identifying hotspots at a

290 coarse scale is still useful for conservation planning; the hotspots identified here should

291 now be priorities for finer scale assessments (Rodrigues et al. 2004). Further, we are in an

292 era of species on the move, as species shift their geographic distributions in response to

293 anthropogenic change (Chen et al. 2011; Freeman et al. 2018). Protecting habitat in high

294 diversity areas provides habitat options that nearby species may well use in the future,

295 even if they don't use them currently.

297 Cells that were hotspots for both at-risk and range-edge taxa are particularly interesting

298 for long term conservation. Since the highest densities of mammals deemed at-risk in

299 Canada occur in the United States (Fig. 1b), one effective conservation strategy for many

300 at-risk taxa in Canada may be to maintain habitat connections to US populations. This

301 would both enable natural immigration and population replenishment, and provide

302 bridges if or when species begin to shift northward in response to warming, both of which

303 could bolster Canadian populations. Indeed, given worldwide range shifts to higher

304 latitudes (Chen 2011), Canada's current range-edge species may become much less

305 peripheral in the coming decades, and much of Canada's future biodiversity may be on

306 our doorstep. Protecting habitat in the 'double hotspots' is a win-win-win, protecting high

307 numbers of mammals overall, protecting the at-risk species to whom Canada deems it has

308 a national responsibility, and protecting Canada's future biodiversity in terms of currently

309 peripheral species and the wildlife refugees from climate change coming our way. 


\section{Supporting Information}

312 SI is available online. Appendix S1 = distributions of species assessed by COSEWIC

313 grouped by COSEWIC threat status. Appendix S2 = grid map of Canada. Appendix S3 =

314 results from analyses exploring sensitivity of hotspot models and from alternate

315 analytical decisions described in Methods. Appendix S4 = AICs of spatial GLMs

316 according to different neighborhood distances. The authors are solely responsible for the

317 content and functionality of these materials. Queries (other than absence of the material)

318 should be directed to the corresponding author. 
321 ArtDatabanken. 2015. The 2015 red list of Swedish species. Uppsala, Sweden.

322 Augustin N, Mugglestone M, Buckland S. 1996. An autologistic model for the spatial

323 distribution of wildlife. The Journal of Applied Ecology 33:339-347.

324 Brown JH, Stevens GC, Kaufman DM. 1996. The geographic range : size, shape,

325 boundaries, and internal structure. Ecology 27:597-623.

326 Buckley LB et al. 2010. Phylogeny, niche conservatism and the latitudinal diversity

327 gradient in mammals. Proceedings of the Royal Society B: Biological Sciences

$328 \quad 277: 2131-2138$.

329 Ceballos G, Ehrlich PR. 2006. Global mammal distributions, biodiversity hotspots, and

330 conservation. Proceedings of the National Academy of Sciences of the United States

331 of America 103:19374-19379.

332 Cheffings CM, Farrell L, Dines TD, Jones RA, Leach SJ, McKean DR, Pearman DA,

333 Preston CD, Rumsey FJ, Taylor I. 2005. Species status No. 7. The vascular plant red 334 data list for Great Britain. Peterborough, UK.

335 Chen IC, Hill JK, Ohlemüller R, Roy DB, Thomas CD. 2011. Rapid range shifts of

336 species associated with high levels of climate warming. Science 333:1024-1026.

337 Coristine LE, Kerr JT. 2011. Habitat loss, climate change, and emerging conservation

338 challenges in Canada. Canadian Journal of Zoology 89:435-451.

339 Dormann C et al. 2007. Methods to account for spatial autocorrelation in the analysis of

$340 \quad$ species distributional data: a review. Ecography 30:609-628.

341 Eckert CG, Samis KE, Lougheed SC. 2008. Genetic variation across species’

342 geographical ranges: The central-marginal hypothesis and beyond. Molecular

$343 \quad$ Ecology 17:1170-1188. 
344 Freeman BG, Lee-Yaw JA, Sunday JM, Hargreaves AL. 2018. Expanding, shifting and

345 shrinking: The impact of global warming on species' elevational distributions.

346 Global Ecology and Biogeography 27:1268-1276.

347 Gaston KJ. 2000. Global patterns in biodiversity. Nature 405:220-227.

348 Gibson S, Van der Marel R, Starzomski B. 2009. Climate change and conservation of

349 leading-edge peripheral populations. Conservation Biology 23:1369-1373.

350 Griffith D, Peres-Neto P. 2006. Spatial modeling in ecology : the flexibility of

351 eigenfunction spatial analyses. Ecological Society of America 87:2603-2613.

352 Hargreaves AL, Eckert CG. 2019. Local adaptation primes cold-edge populations for

353 range expansion but not warming-induced range shifts. Ecology Letters 22:78-88.

354 Hunter ML, Hutchinson A. 1994. The virtues and shortcomings of parochialism:

355 Conserving species that are locally rare, but globally common. Conservation

$356 \quad$ Biology 8:1163-1165.

357 IUCN (International Union for the Conservation of Nature). 2018. The IUCN red list of

358 threatened species. Version 2018-1. Gland, Switzerland. Available from

359 http://www.iucnredlist.org (accessed October 11, 2018).

360 Jenkins CN, Pimm SL, Joppa LN. 2013. Global patterns of terrestrial vertebrate diversity

361 and conservation. Proceedings of the National Academy of Sciences of the United

$362 \quad$ States of America 110:E2603-E2610.

363 Kerr JT, Cihlar J. 2004. Patterns and causes of species endangerment in Canada.

364 Ecological Applications 14:743-753.

365 Kerr JT, Deguise I. 2004. Habitat loss and the limits to endangered species recovery.

$366 \quad$ Ecology Letters 7:1163-1169. 
367 Klemet-N'Guessan S, Jackiw R, Eckert CG, Hargreaves A. 2019. Edgy conservation:

368 Canadian at-risk plants are overwhelmingly range-edge populations and under-

369 studied. bioRxiv:682823.

370 Lawton JH. 1993. Range, population abundance and conservation. Trends in Ecology and

$371 \quad$ Evolution 8:409-413.

372 Le Saout S et al. 2013. Protected areas and effective biodiversity conservation. Science

$373 \quad 342: 803-805$.

374 Lesica P, Allendorf FW. 1995. When are peripheral populations valuable for

375 conservation? Conservation Biology 9:753-760.

376 Mimura M, Aitken SN. 2010. Local adaptation at the range peripheries of Sitka spruce.

377 Journal of Evolutionary Biology 23:249-258.

378 Myers N. 1988. Threatened biotas: "Hot spots" in tropical forests. The Environmentalist

$379 \quad 8: 187-208$.

380 Myers N, Mittermeier RA, Mittermeier CG, Fonseca GAB, Kent J. 2000. Biodiversity

381 hotspots for conservation priorities. Nature 403:853-858.

382 Natural Earth. 2018. Natural earth vector countries. Version 4.1.0. Available from

383 https://www.naturalearthdata.com (accessed September 10, 2018).

384 Orme CDL et al. 2005. Global hotspots of species richness are not congruent with

385 endemism or threat. Nature 436:1016-1019.

386 Pebesma E. 2018. Simple features for R: standardized support for spatial vector data. R

387 Journal 10:439-446.

388 Pironon S, Papuga G, Villellas J, Angert AL, García MB, Thompson JD. 2017.

389 Geographic variation in genetic and demographic performance: new insights from 
an old biogeographical paradigm. Biological Reviews 92:1877-1909.

391 Prendergast JR, Quinn RM, Lawton JH, Eversham BC, Gibbons DW. 1993. Rare species,

392 the coincidence of diversity hotspots and conservation strategies. Nature 365:335-

$393 \quad 337$.

394 R Core Team. 2018. R: A language and environment for statistical computing. R

395 Foundation for Statistical Computing, Vienna, Austria. Available from

396 https://www.r-project.org/.

397 Rassi P, Hyvärinen E, Juslen A, Mannerkoski I. 2010. The 2010 red list of finnish

398 species. Available from: www.nationalredlist.org (accessed June 2019).

399 Reid W V. 1998. Biodiversity hotspots. Trends in Ecology \& Evolution 13:275-280.

400 Ricketts TH et al. 2005. Pinpointing and preventing imminent extinctions. Proceedings of

401 the National Academy of Sciences 102:18497-18501.

402 Rodrigues ASL et al. 2004. Global gap analysis: priority regions for expanding the global 403 protected-area network. BioScience 54:1092.

404 Sagarin RD, Gaines SD. 2002. The "abundant centre" distribution: to what extent is it a

405 biogeographical rule? Ecology Letters 5:137-147.

406 Samis KE, Eckert CG. 2009. Ecological correlates of fitness across the northern

407 geographic range limit of a pacific coast dune plant. Ecology 90:3051-3061.

408 Schipper J et al. 2008. The status of the world's land. Science 322:225-230.

409 Schloss CA, Nunez TA, Lawler JJ. 2012. Dispersal will limit ability of mammals to track

410 climate change in the Western Hemisphere. Proceedings of the National Academy of

$411 \quad$ Sciences 109:8606-8611.

412 Szabo JK, Khwaja N, Garnett ST, Butchart SHM. 2012. Global patterns and drivers of 
413 avian extinctions at the species and subspecies level. PLoS ONE 7:1-9.

414 Thayn JB, Simanis JM. 2013. Accounting for spatial autocorrelation in linear regression

415 models using spatial filtering with eigenvectors. Annals of the Association of

$416 \quad$ American Geographers.

417 Thomas $C$ et al. 2004. Extinction risk from climate change. Nature 427:145-148.

418 Van Rossum F, Vekemans X, Gratia E, Meerts P. 2003. A comparative study of allozyme

419 variation of peripheral and central populations of Silene nutans L. (Caryophyllaceae)

420 from Western Europe: Implications for conservation. Plant Systematics and

$421 \quad$ Evolution 242:49-61.

422 Venables W, Ripley B. 2002. Modern applied statistics with S.Fourth ed. Springer, New

$423 \quad$ York. Available from http://www.stats.ox.ac.uk/pub/MASS4.

424 Yakimowski SB, Eckert CG. 2007. Threatened peripheral populations in context:

425 Geographical variation in population frequency and size and sexual reproduction in 426 a clonal woody shrub. Conservation Biology 21:811-822. 

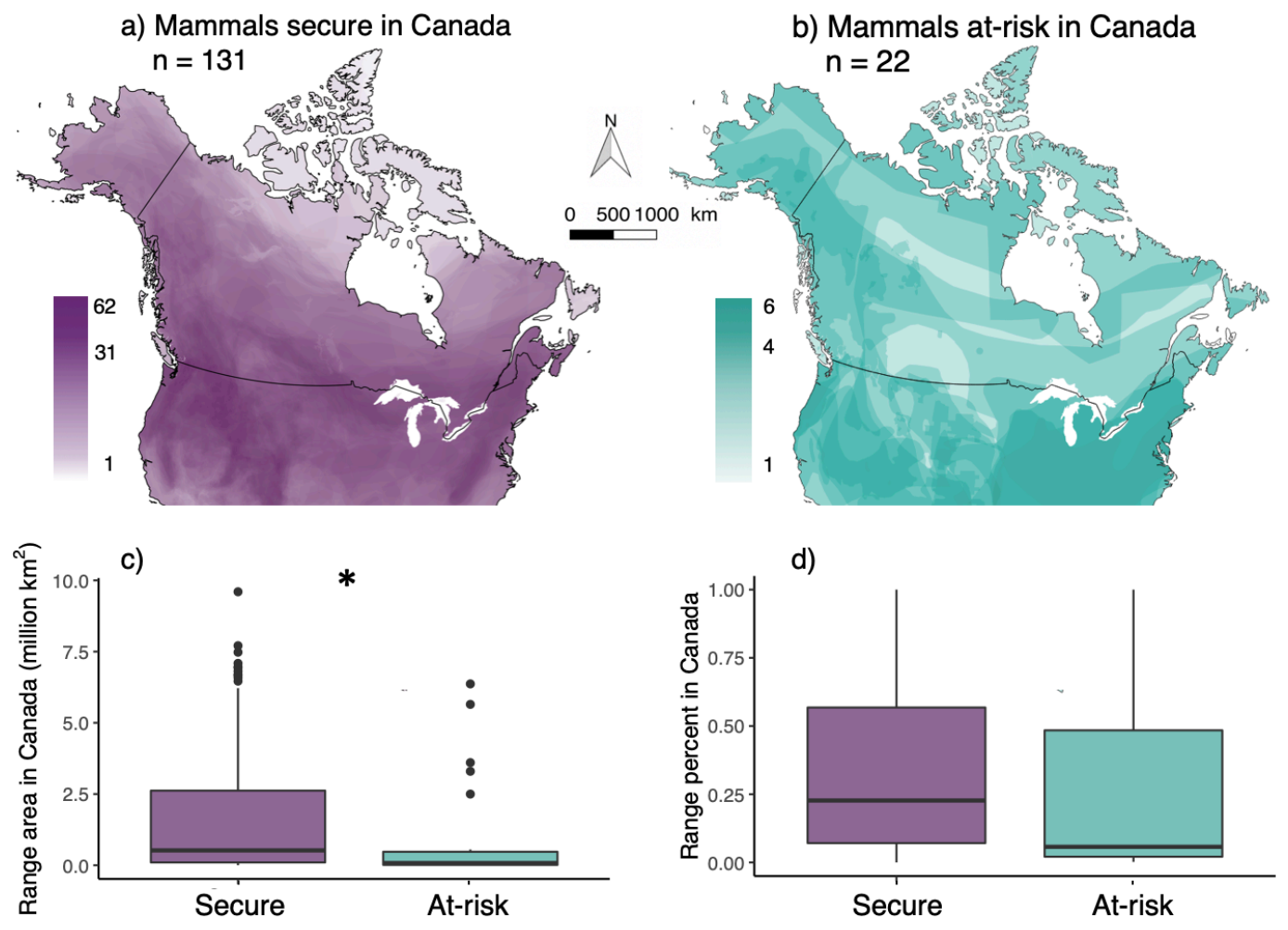

d)

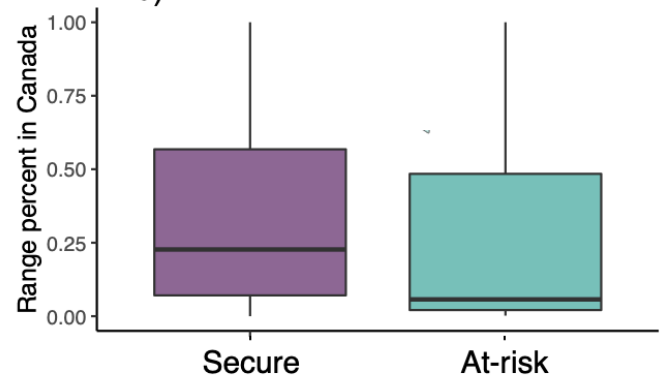

431 Fig. 1: Geographic distributions of terrestrial mammals deemed secure (purple) and at

432 risk (teal) in Canada. (a \& b) Each polygon shows one taxon's distribution, areas of

433 darker colour contain more taxa (colour scale bars indicate species richness). Although

434 only taxa that occur in Canada are mapped, areas of high richness occur south of the

435 Canadian border. At-risk and secure mammals differ in Canadian range size (c; *

436 indicates statistical difference from model considering ln-transformed data), but not the

437 percentage of their global range that occurs in Canada (d). c and d show raw data, centre

438 lines and box boundaries represent the median, $25^{\text {th }}$ and $75^{\text {th }}$ percentiles respectively,

439 whiskers extend to $1.5 \mathrm{x}$ the distance between the $25^{\text {th }}$ and $75^{\text {th }}$ percentiles, dots are

440 outliers. 

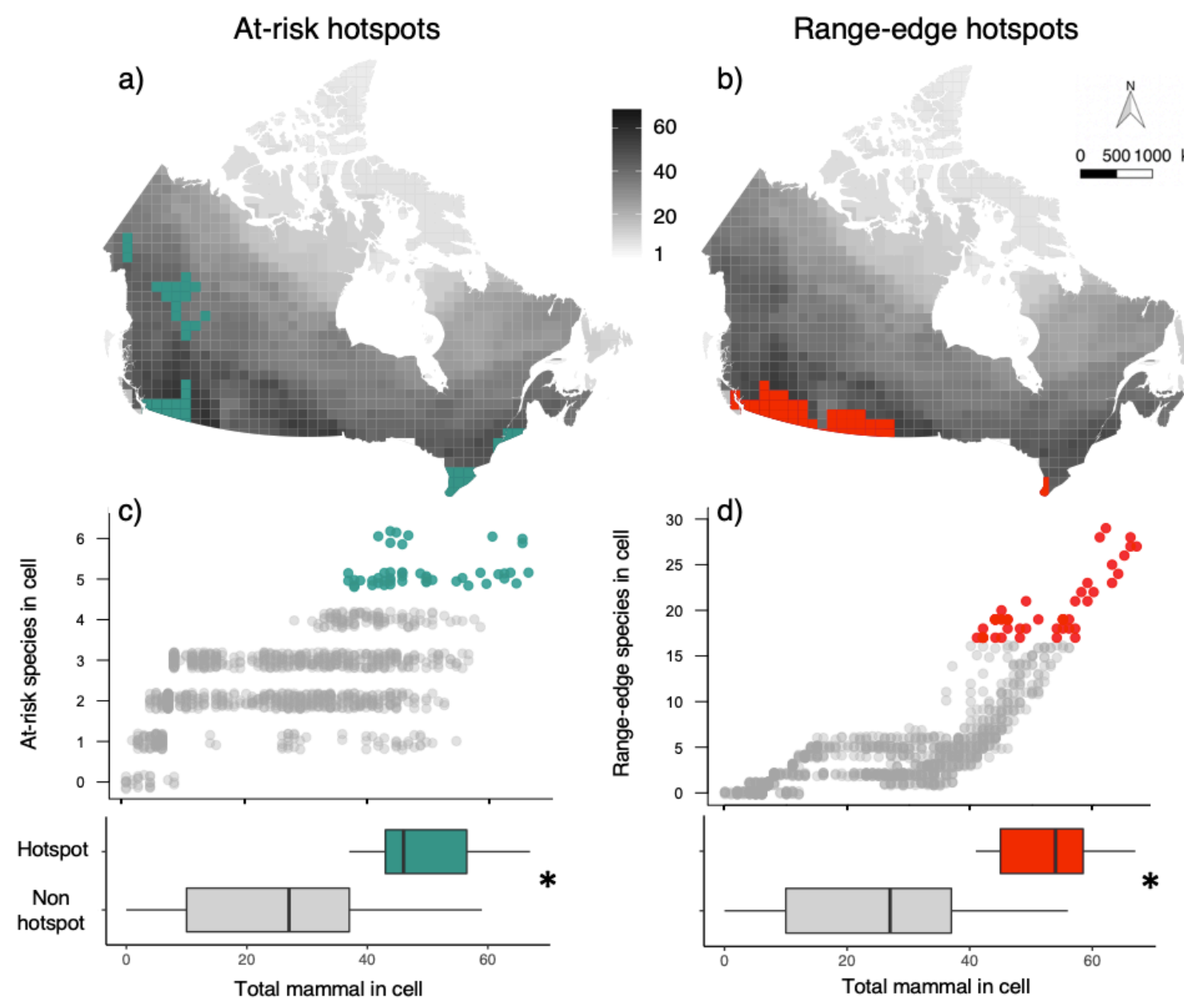

442 Fig. 2: High spatial overlap between hotspots and total mammal richness. Maps of

443 Canada are divided into 1284 100x100 km grid cells, shaded in greyscale to show total

444 species richness of terrestrial mammals. Coloured cells show locations of hotspot cells,

445 i.e. those with the highest richness of a) mammals deemed at-risk in Canada (teal), and b)

446 mammals that only occur in Canada in the northernmost $20 \%$ or less of their global

447 distribution (red). (c \& d) Relative diversity of hotspot (coloured) vs. non-hotspot (grey)

448 cells. Middle plots show raw data, where each point represents one grid cell. Bottom:

449 Hotspots have higher total mammal richness than non-hotspot cells $(*$ indicates a

450 significant difference within panel). Boxes summarize raw data, showing the median and

451 quartiles, formatting as per Fig. 1. 


\section{Appendix S1}

453
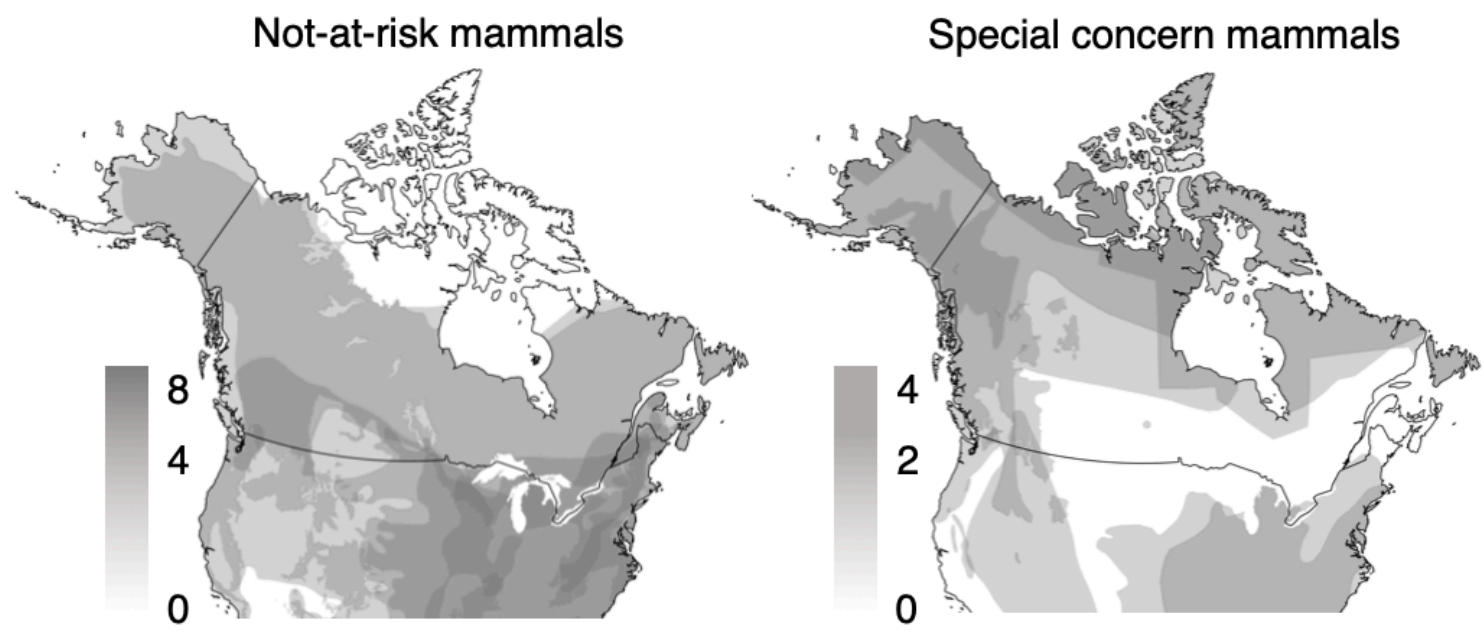

Threatened Mammals
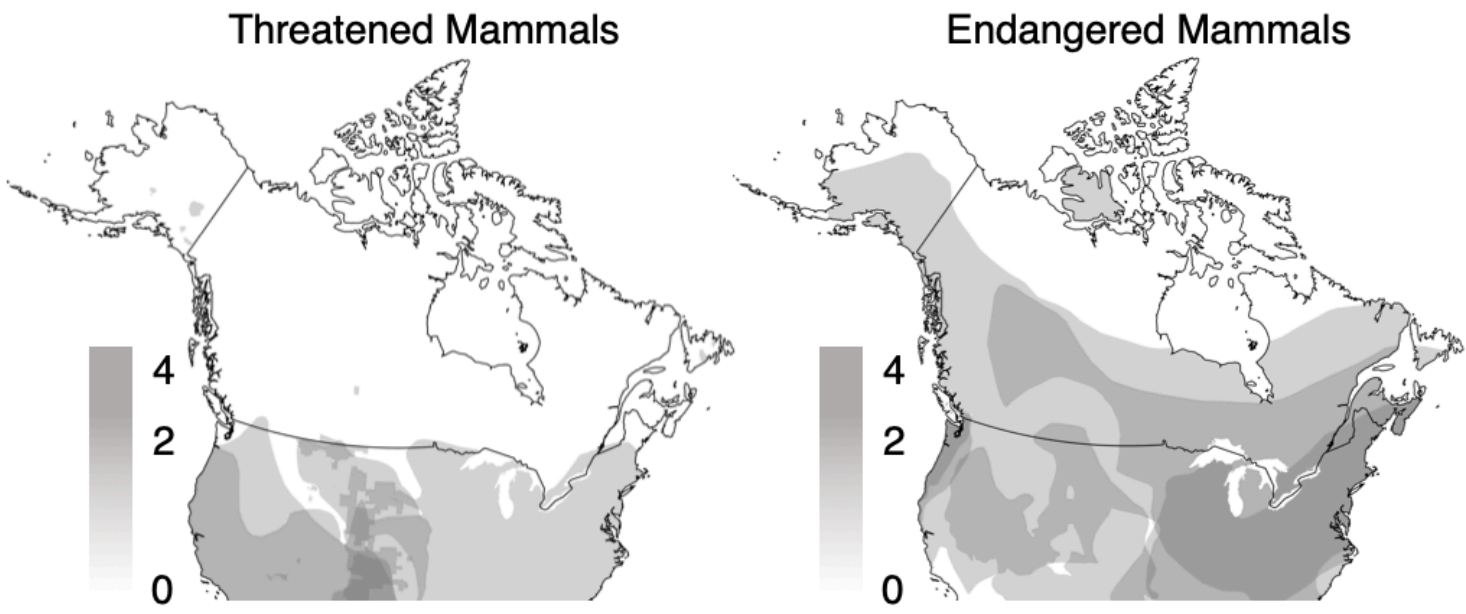

455 Appendix S1: Spatial distribution of the Canadian terrestrial mammals that have been

456 assessed by COSEWIC, separated by their COSEWIC status: Not-at-risk of extinction

$457(n=8)$, Special concern $(n=10)$, Threatened $(n=6)$, and Endangered $(n=8)$. 
bioRxiv preprint doi: https://doi. org/10.1101/2020.0129 925461. this version posted February 72020 . The copyright holder for this preprint (which was not certified by peer review) is the author/funder, who has granted bioRxiv a license to display the preprint in perpetuity. It is made available under aCC-BY-NC-ND 4.0 International license.

\section{$459 \quad$ Appendix S2}

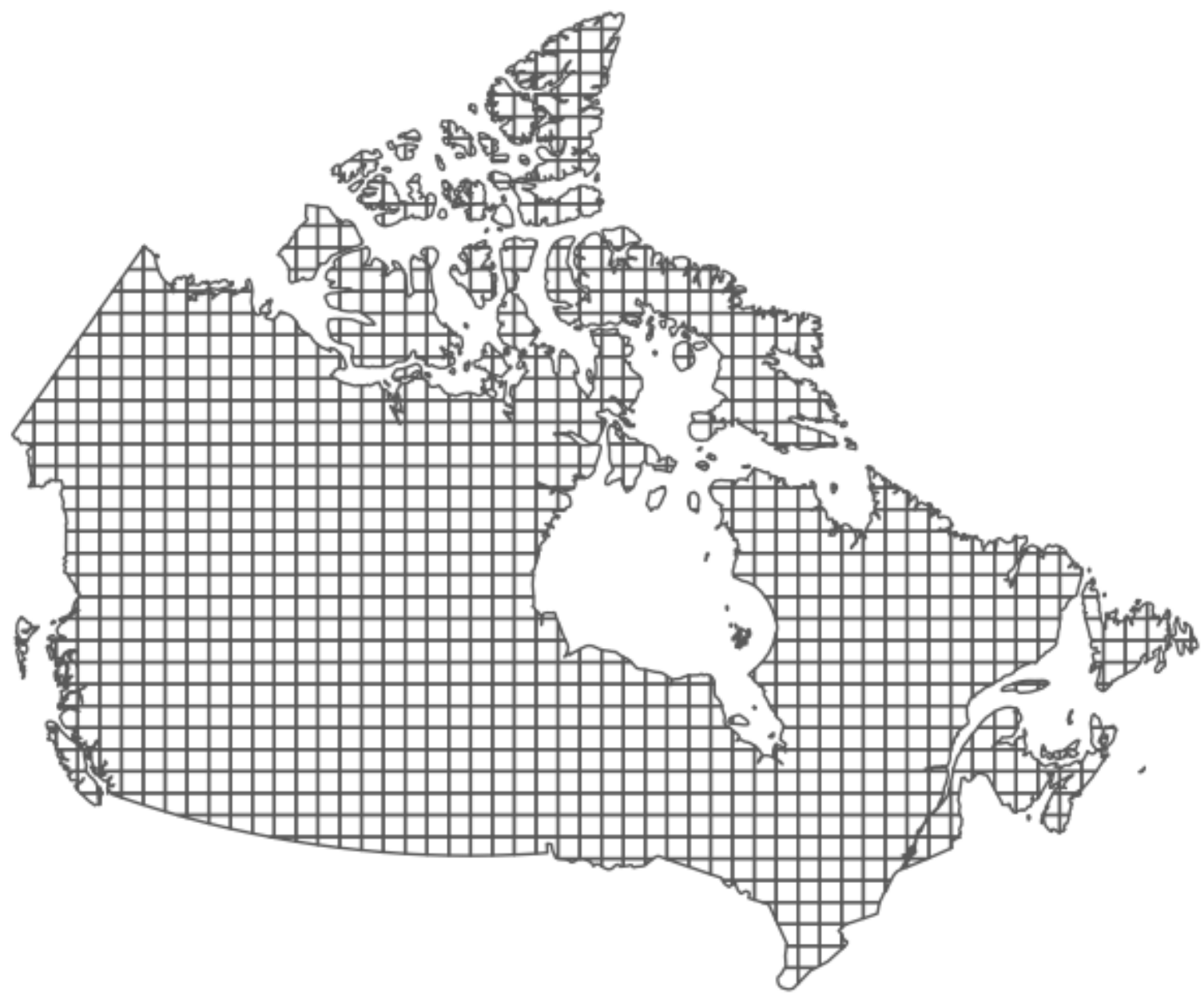

41

461 Appendix S2: Grid map of Canada. The grid is a $100 \times 100 \mathrm{~km}$ cell grid overlapped on

462 the map of Canada projected in an Albers equal area projection. Mammal diversity

463 metrics were calculated for each grid cell for analyses in Question 2 (hotspots). 


\section{Appendix S3}

465 Results from additional models exploring the sensitivity of hotspot analyses. All models

466 compared a binary response (a cell was or was not a hotspot) to a measure of overall

467 richness (fixed effect). Results show the analysis of deviance of each model. Models

468 presented in the main text are in bold. Spatial covariate: Including a term to capture the

469 spatial covariance in the data ( $s$ : Spatial Eigenvector Mapping) improved model fit

470 compared to equivalent models without $s$ (models 1 vs 2 , models 5 vs 6 ). Including $s$ also

471 corrected the autocorrelation in residuals for the at-risk hotspot model (model 2 without

$472 s$ : Moran's $I \pm \mathrm{SD}=0.046 \pm 0.0014, P<0.001$; model 1 with $s$ : Moran's $I \pm \mathrm{SD}=$ -

$4730.00060 \pm 0.0014, P=0.90$ ) and the range-edge hotspot model (model 7 without $s$ :

474 Moran's $I \pm \mathrm{SD}=0.063 \pm 0.0014, P<0.001$; model 6 with $s$ : Moran's $I \pm \mathrm{SD}=-0.0023$

$475 \pm 0.0013, P=0.020)$. Richness of secure mammals vs. all mammals: Comparing richness

476 of secure mammals between hotspots vs. non-hotspots yielded similar results to

477 comparing total mammal richness (at-risk + secure) between hotspots vs. non-hotspots

478 for analyses of at-risk hotspots (model 1 vs 3) and range-edge hotspots (models 5 vs 7).

479 Cell area: Accounting for cell area in models did not change conclusions (models 1 vs 4,

4805 vs 8). Threshold for being considered a range-edge taxon: Reducing the threshold for

481 'range-edge' taxa from $\leq 20 \%$ of their global range in Canada to $\leq 10 \%$ of their range in

482 Canada did not qualitatively change results (model 5 vs 9). 


\begin{tabular}{lrrrr}
\hline Hotspot type & \multicolumn{3}{c}{ Fixed effects } & Model \\
Model) & Effect & $X^{2}{ }_{\mathrm{d}=1}$ & $P$ & AIC \\
\hline
\end{tabular}

At-risk hotspots vs non-hotspots

1)

2)

3)

4)
Total richness $s(\mathbf{1 7 0})^{1}$

Total richness

Secure richness $s(170)^{1}$

Total richness

Cell area

$s(170)^{1}$

Range-edge hotspots vs non-hotspots

\begin{tabular}{rlrrr} 
5) 20\% threshold & $\begin{array}{l}\text { Total richness } \\
\text { s (380) }\end{array}$ & $\mathbf{2 6 6 . 8}$ & $<.0001$ & $\mathbf{7 0 . 3}$ \\
6) $20 \%$ threshold & Total richness & 203.4 & $<.0001$ & 203.9 \\
7) $20 \%$ threshold & $\begin{array}{l}\text { Secure richness } \\
S(350)^{1}\end{array}$ & 281.6 & $<.0001$ & 69.9 \\
8) $20 \%$ threshold & $\begin{array}{l}\text { Total richness } \\
\text { Cell area }\end{array}$ & 269.6 & $<.0001$ & \\
& $S(380)^{1}$ & 2.9 & .089 & 69.4 \\
9) $10 \%$ threshold & $\begin{array}{l}\text { Total richness } \\
S(380)^{1}\end{array}$ & 307.9 & $<.0001$ & 75.8 \\
\hline
\end{tabular}

484

1. Number in brackets is the neighbourhood of $s$ in $\mathrm{km}^{2}$

\section{$140.3<.0001 \quad 94.0$}

$141.2<.0001 \quad 266.1$

$163.7<.0001 \quad 116.9$

$201.6<.0001$

100.9

$16.8<.0001$

. 


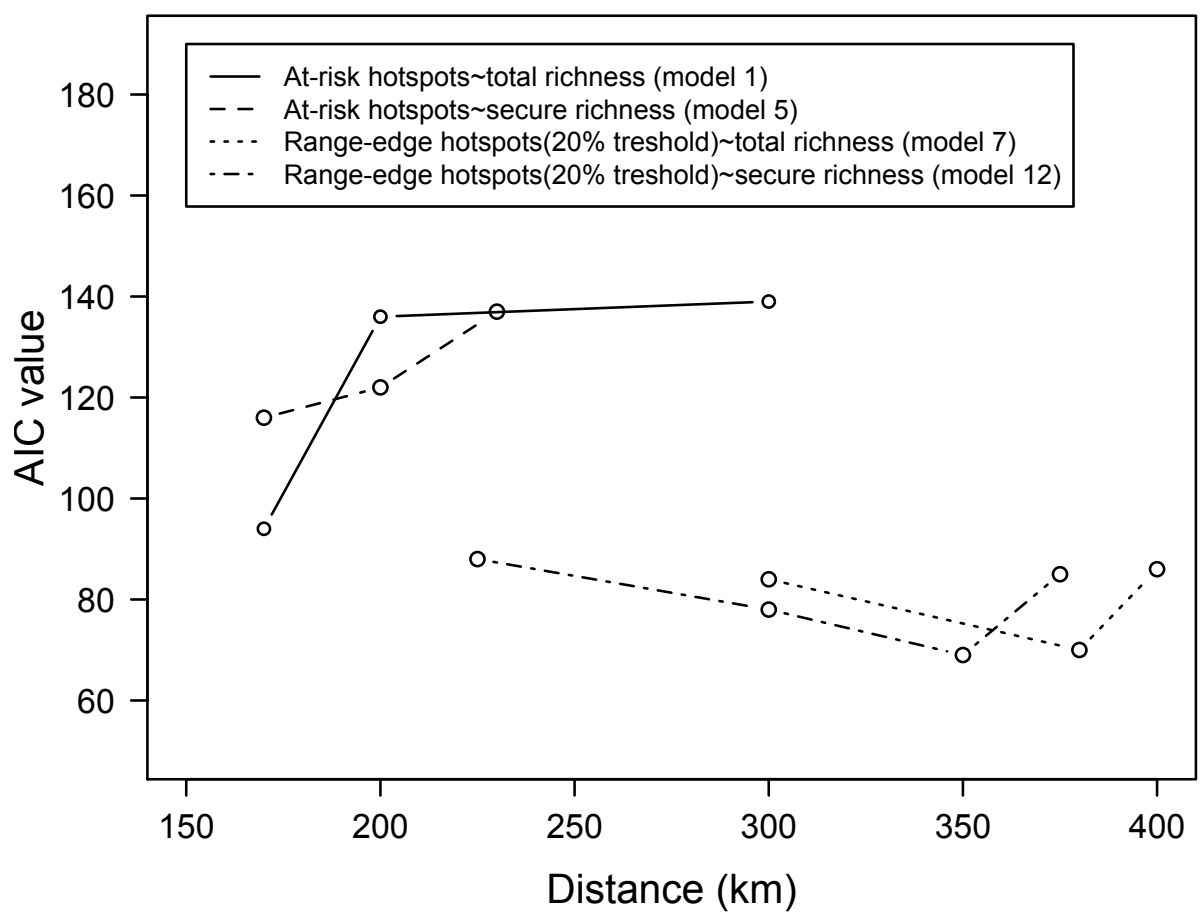

488 Appendix S4: Akaike information criterion (AIC) values for different distances of 489 neighborhood within the spatial extra covariate integrated to GLMs. Neighborhood 490 distances were used to obtain the spatial covariate using Spatial Eigenvector Mapping 491 (SEVM). Absent values indicate distances for which the eigenvector filtering could not 492 yield results. AICs for different distances are presented for all three GLM models 493 presented in the methods. The distance resulting in the lowest AIC was selected for the 494 given model. 